\title{
FORMAÇÃO DE PROFESSORES INDÍGENAS COMO ESPAÇO DE RESISTÊNCIA EDUCACIONAL
}

\author{
Waldinéia Antunes de Alcântara Ferreira ${ }^{1}$ \\ Adriana Oliveira de Sales ${ }^{2}$ \\ Alceu Zoia ${ }^{3}$
}

\begin{abstract}
RESUMO: O presente artigo tem a finalidade de apresentar uma reflexão acerca da formação de professores/as indígenas e suas articulações entre ensino, pesquisa e extensão, trazendo à tona a identificação de uma educação/formação libertadora e emancipatória, criada sob auspícios dos princípios da educação escolar indígena que se constitui como comunitária, diferenciada, bilíngue e específica. O texto produz um diálogo entre duas universidades, a Universidade do Estado de Mato Grosso -UNEMAT e a Universidade Federal da Grande Dourados - UFGD como mediadoras das Licenciatura Interculturais Indígenas e dos demais projetos de resistência pela educação no âmbito da formação inicial e continuada de professores indígenas.
\end{abstract}

PALAVRAS-CHAVE: Formação de professores indígenas. Resistência. Educação Libertadora.

\section{INTRODUÇÃO}

O artigo apresenta o resultado de uma reflexão sobre a formação de professores/as indígenas no contexto da Universidade do Estado de Mato Grosso, especificamente, a Faculdade Indígena Intercultural-FAINDI e a Universidade Federal da Grande Dourados - FAIND. As reflexões se encerram na identificação de formações decoloniais que atendem um projeto que não é exclusivo da universidade, mas a experienciação da concretude em política pública, em atendimento a denúncias dos povos originários sobre os processos tutelares que acontecem dentro das aldeias em diferentes campos, entre eles, a

1 Professora do Programa de Pós-Graduação em Educação (PPGEdu) da Universidade do Estado de Mato Grosso (UNEMAT). Coordenadora do Curso de Pedagogia Intercultural-(FAINDI-UNEMAT). Contato: waldineiaferreira@hotmail.com

2 Professora do Curso de Licenciatura Intercultural Indígena - Teko Arandu da Universidade Federal da Grande Dourados, Mato Grosso do Sul (UFGD).Contato: adrianasales@ufgd.edu.br

3 Professor do Programa de Pós-Graduação em Educação (PPGEdu) da Universidade do Estado de Mato Grosso (UNEMAT). Contato: alceuzoia@gmail.com 
educação escolarizada. Resposta ao Movimento Indígena na reivindicação do direito a uma educação/formações de professores/as que atendessem o contexto de vivências próprias. Compreende no texto a denúncia associada ao anúncio da conquista e do exercício em ser parte colaborativa da construção de formação de professores/as indígenas na perspectiva da educação libertadora, porque, específica, diferenciada, bilíngue, intercultural e comunitária.

Princípios que cabem na educação libertadora por serem elementos mobilizadores de uma educação/formação ultra e intercultural em busca de justiça, direitos e reconhecimentos étnicos. Assim, tratar da formação de professores/as não se distancia da formação humana e das finalidades desta formação. Pois, aprendemos em Paulo Freire que a educação em nada é neutra.

$\mathrm{O}$ artigo busca também, refletir no como as articulações com projetos de pesquisa, ensino e extensão que tem sido mister no apoio à docência, à formação inicial e continuada de professores indígenas. Para tanto, abordamos o Programa Institucional de Bolsas de Iniciação à Docência (PIBID), o projeto Ação Saberes Indígenas na Escola (ASIE), e o Programa de Residência Pedagógica (PRP).

\section{FORMAÇÃO DE PROFESSORES/AS INDÍGENAŠ: DIÁLOGOS DECOLONIAIS}

A formação de professores/as indígenas com o intuito de atender especificamente as escolas indígenas, é muito atual se consideramos o tempo de escolarização e formação de professores/as no Brasil. Essa preocupação relacionada à formação específica para educadores nos respectivos grupos originários resulta dos movimentos indígenas, principalmente, na década de 70, quando se impulsionou debates acerca da criação dos magistérios específicos (GRUPIONI, 2006) e, por conseguinte, cursos superiores em diversas universidades no Brasil. Essa luta produziu uma organização a favor de uma educação intercultural, diferenciada e com respeito as línguas dos povos originários e fez com que se questionasse historicamente como os sistemas de ensino que conhecemos foi construído em bases excludentes, homogêneas e universais, ou seja, colonizadoras.

Um passado recente, nos mostra que a década de 1970 foi marcada por grandes Conferências Indígenas, principalmente em Mato Grosso e Mato Grosso do Sul. Seguiu-se a década de 1980 com um movimento em direção à educação escolarizada. De acordo com Darci Secchi (2009), essa década estabeleceu conexões importantes entre a organização indígena, a reflexão acadêmica e militância indigenista, período também, que se organizou no estado de Mato Grosso a criação do Conselho Educacional Indígena que ocorreu em 1987 e em muitos outros estados do país com a criação dos Núcleos de Educação ou Núcleos de Estudos Indígenas. 
Aos poucos os espaços foram sendo ocupados, ressignificados e criados com a perspectiva de romper o silêncio instalado no terreno social brasileiro. Esse movimento organizativo que foi se ampliando, constituiu-se no enfrentamento à educação escolarizada nos moldes assimilacionista, bancário e catequético, ou seja, um enfrentamento à colonialidade implantada nos interiores das escolas, muito mais àquelas em que estão em comunidades indígenas.

Os movimentos sempre foram, rebuscados de etnopolítica pela busca da apropriação deste espaço. Uma apropriação pensada não apenas na estrutura estatal, mas principalmente na apropriação da política a que esta estrutura se dispõe. Nesse sentido, precisamos mencionar que alterações na proposição filosófica do fazer pedagógico e do fazer professores/as indígenas foi sendo fundamentada nos objetivos da educação escolar indígena que se objetiva: comunitária, específica, diferenciada, intercultural e bilíngue conforme legislação atual.

A Constituição Federal de 1988 e outros documentos que abordam a educação escolar indígena, foram e são elementos importantes na organização de cursos de professores/as indígenas, assim também fundamental para o fazerse professor/a indígena, que geralmente, atende formação em serviço, pois quase sempre os profissionais da educação que atuam nas respectivas escolas de suas comunidades o são, ao mesmo tempo, professores/as e acadêmicos de forma paralela. Assim, geralmente, os cursos específicos de formação de professores/as indígenas ocorrem como formação em serviço, pois esses professores atuam em suas respectivas escolas mesmo antes da sua formação específica para a docência.

Os cursos de formação de professores/as indígenas tem como diretriz legal, a própria Constituição Federal de 1988, assim também a Lei de Diretrizes e Bases da Educação Nacional - LDB 9394/96, esses documentos asseguraram os princípios da educação diferenciada para os povos indígenas, bem como, descrevem as competências para a oferta da educação escolar bilíngue, intercultural, fortalecimento de práticas socioculturais, bem como a manutenção/ revitalização/fortalecimento da diversidade linguística. Ao definir o direito a uma educação específica, possibilita o direito à formação específica de professores/as para atuarem junto ao seu próprio povo dentro de uma perspectiva intercultural, cosmogônica, e, com aplicação de políticas linguísticas.

Soma-se a essas diretrizes legais, no que concerne a formação de professores/ as indígenas, os Referenciais Nacionais para a Formação de Professores indígenas de 2002, que aborda de maneira geral o perfil desse grupo de educadores/ as. Ainda, o Parecer CNE 06/2014 - Diretrizes Curriculares nacionais para formação de professores indígenas; e, a Resolução CNE/CP 01/2015, que institui as Diretrizes Nacionais para Formação de professores Indígenas.

Os primeiros cursos de formação de professores/as indígenas em Mato Grosso foram os magistérios específicos e interculturais, sendo, Projeto Tucum, Pedra Brilhante/Urucum e Rayo, todos oferecidos pela SEDUC-MT. Momento importante vivenciado no estado foi a Conferência Ameríndia de Educação e do Congresso de Professores do Brasil em 1997, promovido pela Secretaria 
de Educação, realizado em Cuiabá/MT. No mês de outubro de 1998 em Mato Grosso, se instituiu uma Comissão Interinstitucional e Paritária para formular um anteprojeto de cursos específicos e diferenciados que atendessem a formação de professores/as indígenas em nível superior. Assim, em 09 de julho de 2001 iniciava no país o primeiro curso de formação de professores/as indígenas em nível de graduação, experiência ocorrida no interior da Universidade do Estado de Mato Grosso - UNEMAT.

Em Mato Grosso do Sul, a formação de indígenas como professores no Etnoterritório do Cone Sul se inicia com o Curso de Magistério Indígena, Ará Verá. Essa formação é específica para os povos Guarani Kaiowá e está amparada pela Secretaria de Educação do Estado, posteriormente, em 2006 houve a criação da Licenciatura Intercultural Indígena Teko Arandu na Universidade Federal Grande Dourados/UFGD. Essa licenciatura, tem como objetivo formar indígenas em nível superior e em 2013 cria-se a partir desse curso a Faculdade Intercultural Indígena FAIND. Os outros sete povos (Atikum, Guató, Kamba, Kadiwéu, Kinikinau, Ofaié e Terena) pertencem ao Etnoterriório Povos do Pantanal, com formação em nível médio "Povos do Pantanal" e nível superior com o mesmo nome, sendo ofertado pela Universidade Federal de Mato Grosso do Sul.

Com o tempo muitas outras universidades assumiram os cursos específicos e também o sistema de cotas para os indígenas, nos casos como da UNEMAT onde $5 \%$ de todos os cursos reservam vagas aos povos originários e na UFGD com uma vaga específica em todos os cursos.

Outro fato a ser considerado é que a partir de 2005 iniciou-se o Programa de Apoio à Formação Superior e Licenciaturas Indígenas- PROLIND, sendo uma iniciativa do Ministério da Educação que tem como objetivo fomentar programas específicos de formação de professores indígenas, em nível superior, que atuam nos anos finais do Ensino Fundamental e no Ensino Médio da Educação Básica das escolas indígenas.

Esse programa conseguiu subsidiar em torno de 19 cursos de Licenciatura e Pedagogias Interculturais nas Instituições de Ensino Superior, e obteve, conforme dados do relatório em 2018, mais de 3.000 matrículas ativas, com número aproximado de 300 egressos na UFGD e há uma crescente demanda ainda por ser atendida.

Pode se dizer que as universidades que atendem as populações originárias de maneira específica, entre elas a UNEMAT e a UFGD, preocupam-se com a produção de uma formação emancipatória fundamentada na interculturalidade, considerando o bi-multilinguismo, as situações sociolinguísticas, as especificidades, as diferenças, enfim os saberes da cultura em diálogo com a academia.

Da perspectiva anti-colonialista, Nobre (2016, p.35) defende que:

A presença dos alunos indígenas nos espaços acadêmicos, trazidos pelas Licenciaturas Indígenas, pode contribuir para que superemos alguns dos nossos ranços colonialistas e incomodar um pouco a estrutura 
"enferrujada" da universidade e, assim, incomodando, construir novas pontes entre nossa ciência e os saberes indígenas, mas de forma menos assimétrica, mais intercultural e diferenciada, como tanto almejamos.

Desta forma, a maioria dos cursos específicos preveem tempos de aprendizagens que se intercalam entre tempo aldeia/comunidade e tempo universidade. Essa forma de organização e os preceitos a serem trabalhados ancorados na interculturalidade, nos saberes que são cosmogônicos e que se articulam com o jeito próprio de ser de cada povo originário, são as articulações construídas não pelo viés político-governamental, mas pela medida decolonizante inserida na premissa da busca de direitos, do rompimento do silêncio, e do processo da escuta de uns com aqueles outros sensíveis a causa.

Podemos citar avanços nos Cursos Específicos de Formação de Professores indígenas, tais como:

1. Melhoria da qualidade do ensino nas escolas indígenas e valorização dos conhecimentos interculturais nas comunidades a partir do professor-pesquisador indígena;

2. Produção de materiais didáticos para escolas indígenas: Ação Saberes Indígenas na Escola;

3. Editais que reforçam a Educação Diferenciada tais como: PIBID e Residência pedagógica.

4. Ingresso de professores indígenas em Programas de Pós-Graduação: Mestrado e Doutorado;

5. Realização de concurso público específico que considerou a formação da Licenciatura Intercultural Indígena da UFGD;

6. Iniciativas de fortalecimento de práticas interculturais nas Instituições de Ensino Superior: revisão de referenciais pedagógicos e divulgação de boas práticas.

\subsection{TEMPO ALDEIA/TEMPO COMUNIDADE NOS CURSOS DE FORMAÇÃO INTERCULTURAL}

No que tange a formação de professores/as indígenas, a Faculdade Indígena Intercultural da Unemat, além de outros cursos de licenciatura, tem o curso de Pedagogia Intercultural. A Universidade do Estado de Mato Grosso está trabalhando com a segunda turma de Pedagogia Intercultural, o respectivo curso apresenta uma organização didática vivenciada presencialmente, com um regime semestral, funciona integralmente e tem a duração de cinco (05) anos. Adentrou na turma atual 50 estudantes indígenas, reunindo uma pluralidade étnica de 18 
povos originários, são eles: Apiaká, Arara, Bakairi, Bororo, Chiquitano, CintaLarga, Irantxe, Juruna, Kayabi/Kawayweté, Mebengôkre, Meynako, Munduruku, Nambikwara, Haliti-Paresi, Rikbaktsa, Tapirapé, Terena e Xavante.

Apesar de darmos evidência ao curso de Pedagogia Intercultural, desde 2001 a UNEMAT atende a formação de professores/as no ensino superior com o curso: Licenciatura Intercultural Indígena, com a finalidade de os/as professores/ as atuarem no ensino médio e ensino fundamental anos finais. Compõem o curso os seguintes graus oferecidos: Licenciatura em Línguas, Artes e Literaturas; Licenciatura em Ciências Matemáticas e da Natureza e Licenciatura em Ciências Sociais. Atualmente, o respectivo curso além de atender estudantes das etnias indígenas citadas na apresentação do curso de Pedagogia Intercultural, tem no corpo discente outras etnias tais como: Waurá, Myky, Karajá, Kuikuro, Kalapalo, Umutina/Balatiponé.

A UNEMAT, na Faculdade Indígena Intercultural já formou 110 em Ciências sociais; 110 em Ciências da Matemática e da Natureza, 96 em Línguas, Artes e Literaturas e 45 em Pedagogia Intercultural, assim são 461 professores formados e 120 em formação atualmente. As entradas de cada curso são únicas e adentra uma nova turma, apenas quando a anterior já foi concluída por completo. Também possibilitou formação de 140 professores indígenas especialistas que cursaram a Especialização Lato Sensu em Educação Escolar Indígena e atualmente, oferece o Programa de Pós-Graduação Stricto Sensu Mestrado Profissional em ensino em Contexto Indígena Intercultural a 20 mestrandos indígenas.

Os Cursos de Licenciatura se organizam em duas grandes dimensões de vivências pedagógicas curriculares, uma denominada de Etapa de Estudos Presenciais e a outra Etapa de Estudos Cooperados de Ensino e Pesquisa Intermediária. A etapa de estudos presenciais é bastante intensiva e ocorrem no período de férias dos professores/as, como já foi dito, os estudantes são professores/as em suas respectivas aldeias. Uma solução para formar professores, mas que de certa forma não é a ideal, pois deve haver contrapartidas institucionais que garantiriam a formação em qualquer tempo. Essas etapas presenciais são realizadas no Campus Universitário da UNEMAT de Barra do Bugres.

A Etapa de Estudos Cooperados de Ensino e Pesquisa - Intermediária. É realizada nos períodos intermediários entre uma etapa intensiva e outra (PPC, 206 ). O curso de Pedagogia Intercultural se articula com atividades de pesquisa, projetos de extensão e atividades de ensino numa perspectiva intercultural. Conforme Silva, Ferreira e Ferreira (2017) tem como meta a formação de educadoras/es reflexivos, conhecedores do contexto socioeconômico, cultural e político do país, da região e da aldeia em que está inserido.

Nessas etapas, há uma atenção bastante especial para o atendimento ao currículo da escola indígena, inclusive apoiando estrategicamente o fortalecimento das línguas indígenas com produção de materiais bilíngue dentro da política linguística dos povos originários, parte desta formação. Compreendemos essa ação como uma significativa e coletiva, e a manutenção das formas próprias de 
aprendizagem e das línguas indígenas representam um "processo de resistência e resiliência pelo revestimento consciente da língua, que ocorre de diversas formas e que se articula em reflexões de memórias e de histórias" (FERREIRA, ZOIA, GRANDO, 2020, p,7) Aliás, as formações das IES aqui evidenciadas são experiências de contraversão a 'ordem escolarizada' imposta. São movimentos libertários nas experienciações do vivido. Uma educação/formação concebida e construída dentro dos contextos de significâncias, algo enraizado porque é parte do contexto. Desta forma, busca-se distanciar dos instrumentos capazes de resistir aos poderes do "desenraizamento", ou seja, distanciamento da educação bancária, antidialógica que se pensa a favor do capital. Ousadamente, entendemos que as formações/educações que foram intencionalmente construídas se quer serem projetos libertadores. Portanto, vivências pedagógicas que almejam resultar em um "trabalho pedagógico crítico, apoiado em condições históricas propícias" (FREIRE, 1975, p. 61).

Assim, as licenciaturas da UNEMAT e da UFGD tem aproximações com características pedagógicas interculturais centradas nos grupos originários com os quais trabalham.

Nessa perspectiva a Licenciatura Intercultural Indígena Teko Arandu, foi pensada como um curso que se desenvolve na perspectiva da Pedagogia da Alternância que, grosso modo, consiste numa formação que ocorre em tempos e espaços distintos (Universidade/Comunidade) num movimento de idas e vindas, o que facilita um trabalho de intervenção pedagógica e social nas comunidades das quais os acadêmicos fazem parte.

O Tempo Comunidade, conforme o Projeto Pedagógico do Curso, 2013, corresponde ao período em que os acadêmicos desenvolvem, em suas aldeias e comunidades, atividades orientadas de ensino, pesquisa e extensão. Nesse momento, os acadêmicos abordam, por meio de atividades propostas, os conhecimentos localmente, contextualizando-os e elaborando-os individualmente e coletivamente em sua prática pedagógica escolar e não escolar.

O Tempo aldeia/comunidade é o fortalecimento da prática da pedagogia indígena, pois representa a presença no mundo contextualizado de cultura própria, sem deixar de estar no mundo mais extenso. Esse lócus de articulação de saberes interculturais é um espaço pedagógico de transgressão, porque desloca a 'universidade' do seu lugar de origem, e em coletividade possibilita a produção de experiências outras. Essa aprendizagem que se dá no coletivo e no espaço da aldeia/comunidade é definida intencionalmente com amorosidade, humildade e rigorosidade pedagógica. Três elementos, entre outros dialetizados por Paulo Freire em Pedagogia da Autonomia (e que são necessários para a constituição autônoma do fazer-se professor(a) em contextos significantes, assim, como o é o contexto das pedagogias indígenas. 


\subsection{PRÁTICAS EDUCATIVAS NAS LICENCIATURAS INTERCULTURAIS}

A formação de professores/as indígenas se articula com vários programas e projetos de ensino, pesquisa e de extensão e um deles que muito colaborou e tem colaborado (ainda que sofreu diminuição) com as Licenciaturas Interculturais são os projetos que compõem o PIBID - Programa Institucional de Bolsas de Iniciação à Docência, do Ministério de Educação. As articulações dos Cursos com as ações do Pibid, se fundem uma vez que atendem aos objetivos do aprimoramento da formação inicial docente com planejamento de práticas pedagógicas interdisciplinares, interculturais e decoloniais porque associam várias áreas do conhecimento, abordam culturas diferentes em processo de alteridade do outro, e, enfrentam com manhas no sentido Freireano, o colonialismo ainda tão forte nos processos capitaneados dentro da educação escolarizada. Essas articulações são feitas nas etapas intermediária, lócus de reflexão no âmbito das aldeias, das escolas das aldeias.

É na etapa intermediária, tempo aldeia e tempo comunidade que "os nexos conectivos do mundo da aldeia e do mundo universitário emaranham-se de tal forma que os estudos se constituem como parte de uma formação estendida [..]" (SILVA, FERREIRA, FERREIRA, 2017, p. 425). Uma formação que se aproxima dos círculos de cultura Freireano porque tacitamente e por finalidades etnopolítica reúne-se o coletivo da aldeia, assim, as etapas intermediárias são coletivizadas em discussões, aprendizagens, compartilhamentos, escutas que ocorrem com as pessoas que moram na aldeia. Traduz se aqui a vivência da partilha de saberes e a predisposição para a leitura de mundos, o mundo da aldeia, o mundo que circunda a aldeia, o mundo no sentido das significações. De maneira complexa no processo da escuta sensível na realização das etapas intermediárias, pontos são levantados por estudantes e equipe de professores/as do Curso, essas escutas auxiliam em proposições outras nas etapas presenciais.

Muitos são os desafios nesse emaranhar constitutivo do curso e do se/ formar-se professores/as indígenas, as relações são complexas, mas acreditamos que a formação é significada o tempo todo, principalmente, porque acreditamos em coletividade aos estudantes que a formação de professores/as precisa estar em conectividade com a educação indígena, em interculturalidade. É fundamental compreender que a decolonialidade no processo escolarizado se pauta nas pedagogias indígenas, ou seja, nessa conectividade da formação de professores/ as e como sabedores da ciência do seu próprio povo ${ }^{4}$. Assim, com desafios e em processo de escuta feita muito fortemente acreditamos na possibilidade de uma formação intercultural e emancipatória.

Uma escuta mediatizada pelo diálogo e pelo reconhecimento de que não há saber mais, porque "não há ignorantes absolutos, nem sábios absolutos.

4 Para ampliar a compreensão dessa conectividade ver as referências que Paulo Freire fez sobre ele em Cartas à Cristina, 1994. 
Há homens que, em comunhão, buscam saber mais" (FREIRE, 1987, p. 81). Saber mais, inclui o reconhecimento da presença dos outros, do outro. Outros, no sentido intracultural que politicamente colaboram com a formação dos professores/as do seu povo, e do outro - outros povos, outras gentes.

A escuta se constitui ferramenta do diálogo, como elemento humanizador e de reconhecimento das diferenças. Portanto, caminho para a construção emancipatória e humanista na conquista de direitos das pedagogias indígenas.

É na interlocução entre universidade e comunidade que as produções de práticas didáticas, elaboração de materiais, escritas de livros paradidáticos acontece, é nesse lugar que experienciamos as pedagogias indígenas. Podemos afirmar que essa alternância de espaços de aprendizado são lócus de elaboração e produção de materiais e vivências específicas, multilíngue e diferenciadas que atendem a intra e a interculturalidade com processo de escuta, memória e inclusão da oralidade como prática pedagógica.

Outro programa que tem auxiliado a formação de professores indígenas no país é O Programa Residência Pedagógica. Criado em meio a polêmicas em seus editais, tem subsidiado, assim como o PIBID, as licenciaturas interculturais, no que tange a pensar espaços educacionais de maneira transgressora. A primeira versão do Programa ocorreu em 2018 e uma outra proposta está em andamento na Licenciatura Intercultural Indígena Teko Arandu.

O que esse programa proporciona na licenciatura indígena, além das bolsas que auxiliam muito na formação dos estudantes é ir além do modo como a universidade pensa o ensino. Mesmo os cursos sendo em áreas de conhecimento, ou trabalhando o ensino de maneira mais holística, os programas em si, oportunizam o repensar de maneira engajada e comprometida com o coletivo.

Segundo o edital do Programa, o (PRP) é uma ação da Coordenação de Aperfeiçoamento de Pessoal de Nível Superior (Capes) no âmbito da Política Nacional de Formação de Professores do Ministério da Educação (MEC) e visa estimular projetos inovadores que articulem teoria e prática, proporcionando aos discentes na segunda metade dos cursos de licenciatura uma aproximação com o cotidiano das escolas de educação básica e com o contexto em que elas estão inseridas, no caso das escolas indígenas a maioria dos bolsistas, já são professores. Para tanto, o PRP é realizado em regime de colaboração entre a Capes, as instituições de ensino superior e as secretarias de educação.

$\mathrm{Na}$ Licenciatura Intercultural Indígena da UFGD, o PRP promove atividades nos tempos universidade e comunidade, tais como:

a) Aplicação de diagnósticos socieducacionais e linguísticos que apresentem a realidade educacional e sociolinguística das escolas indígenas com o intuito de entender a interculturalidade, o bilinguismo e a autonomia da educação escolar indígena.

b) Atividades formativas de didática intercultural e interdisciplinaridade: Oportuniza momentos de formações didáticas em sala de aula para 
que os estudantes entendam princípios e objetivos sociopolíticos pedagógicos e de ensino. "Como" ensinar, "para quem" ensinar, "o que" ensinar e "para que" ensinar. Fatores sociais, étnicos, políticos, culturais e psicossociais no processo entre docência e aprendizagem. Didáticas não indígenas e processos próprios de ensino-aprendizagem Guarani/Kaiowá.

c) Observação de aulas: Estabelecemos atividades em que o bolsista precisa observar aulas nos componentes curriculares das escolas indígenas de ensino fundamental e médio com o objetivo de entender sobre metodologias e estratégias didático-pedagógicas diversificadas. As observações oportunizam o entendimento de conteúdos e atividades complementares, o trabalho com alunos, suas famílias, suas comunidades e os materiais didáticos utilizados nas aulas.

d) Registros didáticos pedagógicos: Desenvolvemos práticas de registro das aulas, seja na forma escrita ou audiovisual, com a intenção de fazer desses instrumentos uma formação da prática de autoavaliação e de autoformação tais como (relatórios, gravação de vídeo aulas, gravação de áudio, seminários, etc).

e) Da teoria à prática escolar diferenciada: Contextualizamos os conteúdos dos componentes curriculares, identificando estratégias para apresentá-los, representá-los, exemplificá-los, conectá-los e torná-los significativos, com base na realidade da educação escolar indígena onde as aprendizagens estão situadas. Saberes escolares e saberes não escolares necessários à docência:

f) Oportunizamos formação em espaços escolares e não escolares das aldeias indígenas. $\mathrm{O}$ intuito é estabelecer relações mais próximas com os mestres tradicionais e as escolas. Fazendo com que o residente interaja em vários espaços de formação e pense uma educação integral em prol da interculturalidade.

Após a formação inicial, se torna necessário dar continuidade as interlocuções com esses estudantes já formados e a Ação Saberes Indígenas na Escola vem justamente suprir mais essa demanda e promover a formação continuada de professores indígenas, priorizando a produção de material didático e a alfabetização em língua materna, considerando a realidade sociolinguística dos povos indígenas atendidos, a partir dos seguintes eixos: a) Letramento em Língua Indígena; b) Letramento em Língua Portuguesa como língua materna; c) Letramento em Língua Indígena ou Língua Portuguesa como segunda língua ou língua adicional e d) Conhecimentos indígenas e artes verbais.

Assim, o grande desafio das equipes (Núcleos) de educadores da ação 'Saberes indígenas na escola' é fazer com que sejam respeitados os direitos dos cidadãos indígenas, a situação sociolinguística das comunidades, que podem ser bilíngues, ou não. Neste caso, qual seria a língua da alfabetização? 
Essas são questões importantes a serem consideradas na formação de todos os envolvidos, na construção de metodologias e produção de material didático para a alfabetização e ensino de línguas indígenas como primeiras e segundas línguas.

No estado de Mato Grosso, o projeto Ação Saberes Indígenas na Escola desenvolve atividades em rede, ou seja, com a participação da UFMT, UNEMAT, CEFAPROS e IFMT, atendem os municípios de Cuiabá, Barra do Garças, Juara, Sinop, Tangará da Serra, Barra do Bugres, Cáceres, atendendo comunidades dos povos: Chiquitano, Xavante, Bororo, Apiaká, Munduruku, Kayabi, Kayapó, Terena, Paresi, Umutina e Nambikuara. As coordenações das parcerias são das IES e outras Instituições que têm disponibilizado quadro docente para tal. A seleção desses povos, bem como o agrupamento proposto, se dá na medida em que são firmadas parcerias com técnicos e pesquisadores ligados às instituições envolvidas.

Cada equipe de trabalho que compõe a rede que se realiza no Estado de Mato Grosso para atender inicialmente 10 povos indígenas, é vinculada às escolas indígenas das aldeias dos povos acima citados a serem atendidas numa organização de polos que agregam professores e pesquisadores ou lideranças indígenas - definidos por suas comunidades, e técnicos e professores não indígenas que se disponibilizaram com o aval de suas respectivas instituições para o trabalho de formação.

As formações coadunam e dialogam com a Faculdade Indígena Intercultural, formando rede de diálogos e aproximações das compreensões de formações, ainda que continuada, ou seja, formação que atende a promoção de uma educação escolar indígena emancipatória e humanista.

São formações que se articulam no coletivo, e em diálogo que não ocorrem apenas na formação inicial, mas também na continuada porque esse complexo se emaranha em complementaridade e na compreensão do inacabamento. Assim, compreendemos que a formação de assenta na construção de uma educação que é permanente, conforme nos ensina Paulo Freire (2001, p.12)

A educação é permanente na razão, de um lado, da finitude do ser humano, de outro, da consciência que ele tem de sua finitude. Mais ainda, pelo fato de, ao longo da história, ter incorporado à sua natureza não apenas saber que vivia, mas saber que sabia e, assim, saber que podia saber mais. A educação e a formação permanente se fundam aí.

Como colaboradores/as nesta formação de professores/as compreendemos que a forma de vivenciar as experiências nos cursos de formação, nas atuações nos projetos e na própria construção do fazer-se educadores e educadoras concebese a resistência da permanente formação, que não o é apenas institucional, mas também étnica. Formações e compreensões filosóficas da incompletude, portanto, em busca do "ser mais". 
Temos identificado, via projeto, que as escolas indígenas carecem de materiais didáticos apropriados e desenvolvidos para contar e registrar a história do povo. Com este trabalho colaboramos com o desenvolvimento da pesquisa, da produção e dos registros dos conhecimentos dentro das aldeias, elaborando materiais didáticos que serviram como apoio para as atividades de ensino e pesquisa nas salas de aula, elevando o conhecimento da cultura e da língua de cada povo envolvido no projeto, uma vez que a grande reinvindicação destas comunidades é que se registrem os saberes culturais ancestrais para que as crianças e jovens possam ter acesso direto a estes saberes, analisando e respeitando os princípios educativos de cada povo.

Por meio dessas iniciativas entendemos melhor o que é a deconialidade do saber e entendemos de fato o que é transcender a manutenção da organização social das universidades e dos cursos de graduação. Pois os cursos universitários e os editais governamentais, são geralmente baseados no colonialismo, ou seja, se baseiam nos conhecimentos gerados pelas elites, científicas e filosóficas.

Nas Licenciaturas Interculturais e nos programas e projetos desenvolvidos nesses cursos, podemos perceber o que Bell Hooks (2013), no diz sobre ensinarmos a transgredir, ver a educação como prática da liberdade. Ela presenta a ideia de Pedagogia Engajada como o modo de uma educação progressista e holística de maneira que a educação seja entendida como prática libertadora pois está ligada ao crescimento intelectual e espiritual com conscientização e engajamento crítico. Tem suas bases, principalmente, nos escritos de Paulo Freire. Essa prática conduz o professor a acreditar não na partilha de informações, mas no crescimento holístico dos alunos. Causa estranhamento em professores que não consideram o ensino e os estudantes como seres humanos "integrais".

As experiências pessoais e profissionais relatadas teoricamente já marca em si a transgressão na academia onde a visão recorrente é de que a teoria precisa estar distante de si. Aborda Paulo Freire e o monge budista vietnamita Thich Nhat Hanh como dois professores de alma e corpo. E, a partir desses ensinamentos, desafiam a "educação bancária", onde a abordagem é baseada na noção de que tudo o que os alunos precisam é consumir a informação dada por um professor e ser capaz de memorizá-la.

Já a educação libertária, engajada, como aponta a autora, está baseada no trabalho coletivo, onde tem-se o agir e o refletir sobre o mundo, afim de modificá-lo, e que os alunos liguem a consciência à prática e ainda, põe em evidência a integridade, uma visão de mente, corpo e espírito. Nesse viés, a sala de aula é tida por professores e alunos como seres humanos plenos, buscando não somente o conhecimento que está nos livros, mas também o conhecimento acerca de como vivemos no mundo. Significa que deve haver um compromisso ativo com o processo de autoatualização e que promova o seu próprio bem-estar.

Assim, toda sala de aula em que for aplicado um modelo holístico de aprendizado será também um local de crescimento para o professor, que será fortalecido e capacitado por esse processo. Em Morin (2006), apresenta-se alguns 
desafios para que haja uma educação sistêmica. Afirma que há inadequações, profundas e graves nos saberes separados, fragmentados, compartimentados, pois as realidades e os problemas são polidisciplinares, transversais, multidimensionais. Apresenta o problema da hiperespecialização, que impede de sermos globais, bem como essencial, a inteligência se fraciona e separa o mundo, atrofiando as possibilidades de compreensão e reflexão. Hooks (2013), contrapõe a ideia de hiperespecialização com a autoatualização, afirmando que o professor que faz essa escolha é capaz de criar práticas pedagógicas que envolvam os alunos, proporcionando maneiras de saber que aumentem sua capacidade de viver profunda e plenamente.

Os desafios por ele apresentados para organização do saber, tais como o desafio cultural, no sentido de repensarmos a separação entre a cultura das humanidades e a cultura científica, assim como Hooks (2013), aponta com a diferenciação com o ser intelectual e o papel da academia, como uma cisão entre essas partes. Também o desafio sociológico, onde o pensamento é o capital mais precioso do estudante e para a sociedade onde está inserido, o desfio cívico, como sendo o senso de responsabilidade coletiva, comunitária e o desafio dos desafios com a intenção filosófica de refletir sobre como a reforma do ensino deve levar a reforma do pensamento e à reforma do pensamento deve levar à reforma do ensino.

Dessa forma teríamos uma educação voltada para uma organização dos conhecimentos de maneira a termos um novo espírito científico, voltado para as complexidades, para a ciência sistêmica, a ecologia, a ciência da terra, rompendo assim, com o dogma reducionista do ensino.

Nesse diálogo, por uma pedagogia engajada, libertadora, consciente e voltada para o bem-viver, podemos citar a resistência por uma educação escolar indígena. Hooks (2013) não cita esse aspecto como exemplo no texto, mas acreditamos ser pertinente por se tratar de espaços de ensino transgressor com vistas a educação engajada. Uma pedagogia que tem a artesania "na teimosia, na luta diária, na retomada e no movimento, se instaure uma revolução viva e permanente" (PASSOS, 2008, p. 416). Por outro lado, uma vivência pedagógica que considera o coletivo e que se movimenta entre o intra e o intercultural com ações mediatizadas pelo diálogo com o outro.

\section{CONSIDERAÇÕES FINAIS}

As Licenciaturas Interculturais Indígenas em todo Brasil têm suas raízes nos movimentos indígenas, nasceram por meio de lutas em defesa dos direitos constitucionais que na maioria das vezes são marginalizados e negligenciados. Por si só, o nascer é transgressor, é resistente, frente as formas de organizações não indígenas.

Sendo assim, o que se tentou trazer nesse texto é que esses cursos além de terem se expandido nas últimas décadas, tem feito oposição ao ensino não 
indígena e ensinado que uma educação que não se pensa no bem estar como um todo do ser humano, é uma educação falha. Fadada ao insucesso. Dessa forma, a Educação escolar indígena, seja no nível fundamental, médio ou superior, se põe em xeque e faz pensar:

1. Faz reconhecer os espaços ocupados pela língua portuguesa na vida da sociedade indígena e faz com que haja uma avaliação, em que grau está a presença da língua majoritária e como está afetando a vitalidade das línguas indígenas;

2. Faz com os sistemas de ensino discuta a diversidade e que a sociedade brasileira é composta por várias sociedades diferentes, com culturas diferentes, diversos saberes e formas de ver o mundo;

3. Faz com que as populações indígenas discutam as influências da educação e das escolas nas culturas, seja na educação das novas gerações, seja no fortalecimento ou no enfraquecimento dos conhecimentos próprios dos povos indígenas;

4. Faz alerta às populações indígenas com relação à valorização e ao fortalecimento das línguas indígenas e que não basta saber falar a língua indígena, é preciso mantê-la forte frente à língua majoritária;

5. As Licenciaturas Interculturais ensinam que sim, é possível fazer seleção de ingresso nas universidades de maneira acolhedora e não excludente. Prova disso são os vestibulares diferenciados;

6. Os projetos vinculados aos povos indígenas conseguem partir das vivências das pessoas e das comunidades;

7. O ensino de maneira transversal começa ganhar mais entendimento nas escolas não indígenas.

Dentre outros ensinamentos que podemos elencar sobre a educação escolar indígena que teve sua especificidade fortalecida a partir de 1999, com o Parecer CNE/CEB no 14/1999, aprovado em 14 de setembro de 1999 - Dispõe sobre as Diretrizes Nacionais para o funcionamento das escolas indígenas e com o aumento das escolas em comunidades, além de cursos específicos para a formação de professores indígenas.

Compreendemos que o processo de resistência, que é fortalecimento e processos de reconhecimento, e, acesso à justiça e direitos atende a construção da educação libertadora em contextos que outrora e as vezes ainda o são marginalizados e inferiorizados, ou seja, espaço colonizador e colonizante que se movimentam para a decolonialidade pela autonomia daqueles que produzem as mudanças nos seus lugares de origem.

Nesse sentido, educar-se para a liberdade é educar-se para a humanização, aliás para Paulo Freire não há educação libertadora sem enfrentamento às desumanizações. Educar-se libertariamente é fazer a passagem da consciência ingênua para a consciência crítica, nesse sentido tomar consciência e fazer a 
tomada do lugar no mundo como protagonistas de direitos. Esse movimento de humanização no interior da educação escolarizada é o movimento decolonial na construção de formações/educações que se dão em experiências do vivido na busca do ser mais, e de estar no mundo.

Além do processo claro de resistência ao ensino do não indígena, até então, imposto a essas populações. Esses povos, tem assumido sua educação escolar e ensinado aos não indígenas, como se deve pensar o ensino para o bem-viver de fato.

\section{REFERÊNCIAS}

BRASIL. Constituição da República Federativa do Brasil. Brasília, DF: Senado Federal: Centro Gráfico, 1988.

BRASIL. Lei de Diretrizes e Bases da Educação Nacional - LDB 9394/96.

BRASIL. Parecer CNE 06/2014. Diretrizes Curriculares nacionais para formação de professores indígenas, 2014.

BRASIL. Resolução CNE/CP 01/2015. Diretrizes Nacionais para Formação de professores Indígenas, 2015.

BRASIL. Parecer CNE/CEB $n^{\circ}$ 14/1999. Diretrizes Nacionais para o funcionamento das escolas indígenas, 1999.

FREIRE, Paulo. A educação na cidade. 5. ed. São Paulo: Cortez, 2001.

FREIRE, Paulo. Educação como prática de liberdade. Rio de Janeiro: Paz e Terra: 1975, 148p.

FREIRE, Paulo. Pedagogia do Oprimido. Rio de Janeiro: Paz e Terra, 1987.

FREIRE, Paulo. Pedagogia da autonomia: saberes necessários à prática educativa. São Paulo: Paz e Terra, 1996

FREIRE, Paulo. Cartas à Cristina. São Paulo: Paz e Terra, 1994.

FERREIRA, Waldinéia Antunes de Alcântara. ZOIA, Alceu. \& GRANDO, Beleni Salete (2020). Aprendizagens dos saberes indígenas na escola: Desafios para a formação de professores/as indígenas. Arquivos Analíticos de Políticas Educativas, 28(165). https://doi.org/10.14507/epaa.28.4790 
GRUPIONI, Luis Donizete Benzi. Contextualizando o campo da formação de professores indígenas no Brasil. In: GRUPIONI, Luis Donizete Benzi. Formação de professores indígenas: repensando trajetórias. Brasília: Ministério da Educação, Secretaria de Educação Continuada, Alfabetização e Diversidade, 2006.

HOOKS, Bell. Ensinando a Transgredir: a educação como prática da liberdade. Trad. Marcelo Brandão Cipolla. São Paulo:Ed. WMI Martins Fontes, 2013.

MORIN, Edgar. A cabeça bem-feita: repensar a reforma, reformar o pensamento. Rio de Janeiro, Bertrand Brasil, 2006.

NOBRE, D. Entre a escola e a casa de reza: infância, cultura e linguagem na formação de professores indígenas guarani. Niterói: Eduf, 2016.

PASSOS, Luiz Augusto. (2008) Trama (verbete). In D. Streck, E. Redin, \& J. J. Zitkoski (org). Dicionário Paulo Freire (pp. 415 - 416). Belo Horizonte: Editora Autêntica.

SECCHI, Darci. Gestão escolar indígena: cenários e perspectivas. Cuiabá: EdUFMT, 2009.

SILVA, A. A. da; FERREIRA, W. A. de A.; FERREIRA, L. L. As Etapas Intermediárias como espaço de formação na Licenciatura Intercultural: interações e nexos entre Aldeia-Universidade. Revista de Educação Pública, [S. 1.], v. 26, n. 62/1, p. 421-432, 2017. DOI: 10.29286/rep.v26i62/1.5003. Disponível em: https://periodicoscientificos.ufmt.br/ojs/index.php/educacaopublica/ article/view/5003. Acessado em 18/03/2021. 


\title{
LA FORMACIÓN DE PROFESORES INDÍGENAS COMO ÁREA DE RESISTENCIA EDUCATIVA
}

RESUMEN: El propósito de este artículo es presentar una reflexión sobre la formación de maestros indígenas y sus vínculos entre docencia, investigación y extensión, poniendo en primer plano la identificación de una educación / formación liberadora y emancipadora creada bajo los auspicios de los principios de Educación escolar indígena que se constituye como comunidad, diferenciada, bilingüe y específica. El texto produce un diálogo entre dos universidades, la Universidad Estatal de Mato Grosso -UNEMAT y la Universidad Federal de Grande Dourados - UFGD como mediadoras de las Licenciaturas Interculturales Indígenas y de otros proyectos de resistencia para la educación en el ámbito de la formación inicial y continua del profesorado indígena. pueblos.

PALABRAS CLAVE: Formación de professores indígenas. Resistencia. Educación liberadora.

\section{TRAINING OF INDIGENOUS TEACHERS AS AN EDUCATIONAL RESISTANCE AREA}

\begin{abstract}
The purpose of this article is to present a reflection on the training of indigenous teachers and their links between teaching, research and extension, bringing to the fore the identification of a liberating and emancipatory education / training created under the auspices of the principles of school education indigenous that is constituted as community, differentiated, bilingual and specific. The text produces a dialogue between two universities, the State University of Mato Grosso -UNEMAT and the Federal University of Grande Dourados - UFGD as mediators of Indigenous Intercultural Licentiate degrees and of other resistance projects for education in the scope of initial and continuing teacher training indigenous peoples.
\end{abstract}

KEYWORDS: Training of indigenous teachers. Resistance. Liberating Education. 